\title{
Access to health records: psychiatric patients and patients with diabetes compared
}

\author{
Arun Jha, Morris Bernadt, Ken Brown, Elizabeth Sawicka and \\ George Stein
}

\begin{abstract}
This study was undertaken to assess whether psychiatric patients respond more adversely to reading their own records than non-psychiatric patients. Seventy-three psychiatric out-patients and 84 out-patients with diabetes were posted their main clinical summary with a questionnaire about it. For seven of the eight questions, more than $70 \%$ of both patient groups gave fovourable ratings. However, the psychiatric patients gave significantly less favourable responses than the patients with diabetes on five of the eight questions. Fourteen of $73(19 \%)$ psychiatric patients were upset by reading the clinical summary about themselves compared with four of $84(5 \%)$ patients with diabetes.
\end{abstract}

By law, patients have had the right of access to their own medical records since November 1991. However, the Access to Health Records Act 1990 states that access shall not be given where in the opinion of the holder of the record, information is 'likely to cause serious harm to the physical or mental health of the patients or of any other individual.' Nowhere in the Act is 'serious harm' defined, nor is it clear how information can cause physical harm. Therefore the assumption must be that it is principally harm to the mental health of the patient that would warrant withholding of access.

Before the Act was formulated, the Royal College of Psychiatrists had argued for a total exemption of psychiatric patients from access on the grounds that psychiatric records contained information that was more sensitive and confidential than other medical records, that psychiatric patients might be a more vulnerable group, and that psychiatric records contained more third-party information (Priest, 1986). Although favourable empirical studies of psychiatric patients given access (Stein et al, 1979; McFarlane et al, 1980; Roth et al, 1980; Miller et al. 1987; Parrot et al, 1988; Essex et al, 1990; Price et al, 1990; Bernadt et al, 1991; Kosky \& Burns, 1995) far outnumber the unfavourable (Altman et al, 1980, Sergeant, 1986) these uncontrolled studies do not compare psychiatric patients with other patient groups.

In two general practices there was passing mention of those with psychiatric disorder faring worse than others when given access (Baldry et al, 1986; Bird \& Walji, 1986). A study of hospital psychiatric records compared to general medical ones showed the psychiatric records had two to three times more 'offensive' and 'extremely offensive' comments when rated by five staff and two patients (Crichton et al, 1992). However, no systematic comparison of psychiatric and medical patients given access to their own records exists. Do psychiatric patients fare worse? To address this question we have compared psychiatric patients' and patients with diabetes responses to their reading the main written clinical summary about themselves.

\section{The study}

Psychiatric patients and those with diabetes were consecutive attenders at different clinics in the same district general hospital. Before recruitment of patients we asked the physician (K.B.) and psychiatrist (G.S) whether any patient ought not to see their own records. At the end of the clinic, a previously written full clinical assessment (e.g. the first out-patient letter or in-patient discharge summary) was selected from the case notes, and an unedited copy was posted to the patient along with a questionnaire. Patients did not have access to other parts of the record. The questionnaire was identical to the one used in a previous study (Bernadt et al, 1991), and contained eight questions about the written summary. Most of the questions had five options; the ordinal scales for each question were constructed using published guidelines (McKenzie \& Charlson, 1986). The questionnaire stems are shown in the appendix. We also recorded marital status and social class (Office of Population Censuses and Surveys, 1970). 
To achieve a statistical power of $80 \%$ for a $\chi^{2}$ test with one degree of freedom and a criterion of $P=0.05$ we required a total of 157 patients to detect a small-sized difference between groups and 78 patients to detect a medium-sized difference (Cohen, 1969). We used non-parametric statistics throughout. For logistic regression analysis (Norusis, 1990) we used forward stepwise variable selection. The study had the approval of the Bromley Ethics Committee.

\section{Findings}

Of 85 patients with diabetes, 84 agreed to participate and all of them completed the study. Of 85 psychiatric patients three were not recruited on the advice of the consultant psychiatrist (G.S.), three declined to participate, and six did not return the questionnaire despite reminders. Thus 73 psychiatric patients completed the study. Table 1 shows the demographic characteristics of the psychiatric patients and those with diabetes.

The psychiatric patients were significantly younger. Most of our questions had five options, but very few patients chose the most unfavourable options. Therefore we created binary measures for all questions with the two most favourable options contrasted with the remaining options.

Table 2 shows that four of the eight questions elicited favourable responses less commonly in psychiatric patients than in patients with diabetes. These questions concerned the upset caused by the summary, whether it was a good idea to have been granted access, the accuracy of the summary, and wrong emphasis. However, even with the psychiatric patients more than $70 \%$ gave favourable ratings for seven of the eight questions. For both of the patient groups, the

Table 1. Demographic characteristics of patients: values are counts (\%) unless stated otherwise

\begin{tabular}{lll}
\hline Characteristic & $\begin{array}{l}\text { Psychiatric } \\
\text { patients } \\
(n=73)\end{array}$ & $\begin{array}{l}\text { Diabetic } \\
\text { patients } \\
(n=84)\end{array}$ \\
\hline $\begin{array}{l}\text { Mean age in years } \\
\text { Males }\end{array}$ & $\begin{array}{l}44 \text { s.d. } 14 \\
\text { Marital status }\end{array}$ & 53 s.d. 18 \\
$\quad$ Single & $27(56)$ & $42(50)$ \\
$\quad$ Married & $28(38)$ & $18(21)$ \\
$\quad \begin{array}{l}\text { Separated/divorced } \\
\text { Widowed }\end{array}$ & $16(22)$ & $7(83)$ \\
Socio-economic class & $2(3)$ & $6(7)$ \\
$\quad$ Class i, ii and iii & $37(51)$ & $54(64)$ \\
Class iv and $v$ & $36(49)$ & $30(36)$ \\
\hline
\end{tabular}

1. Mann-Whitney U-test: $Z=-3.4, P<0.001$. worst rating was for the item about whether the summary conveyed helpful information.

To assess whether age, gender, marital status or social class might have contributed to the patient group differences shown in Table 2, we performed for each question a logistic regression on the combined group of 157 patients with the patient group as a fifth variable. Logistic regression confirmed that for the four significant questionnaire items in Table 2, patient group was the only significant variable (i.e. age, gender, marital status, and social class were not significant and were not included in the final logistic regression equation). Logistic regression elicited two further significant findings; for the question on omissions from the summary, patient group became statistically significant when age, gender, marital status, and social class were controlled for (i.e. the psychiatric patients gave less favourable rating than the patients with diabetes). Second, for the question on helpful information conveyed by the summary, age emerged as the only significant variable (i.e. younger patients gave less favourable ratings).

\section{Comments}

Ours is the first systematic comparison of psychiatric with non-psychiatric patients given access to their own records. Psychiatric patients less commonly gave favourable ratings than patients with diabetes on five of the eight questions (omissions from the summary, upset caused by it, whether it was a good idea to have been granted access, the accuracy of the summary, and wrong emphasis). Despite these differences between patient groups, Table 2 shows that even for the psychiatric group by far the majority of responses were favourable.

Well before the Access to Health Records Act 1990, general practitioners in south London allowed patients to see their records while they waited to see the doctor (Baldry et al, 1986). The $10 \%$ upset by reading their notes "were mainly people who had psychiatric problems in the past". Similarly in an inner-city Birmingham general practice (Bird \& Walji, 1986), 12 patients $(0.3 \%$ of the practice population) were denied free access to their notes; of the four categories of embargo, one was " . . .the severely disturbed patient. The occasional patient is so unwell psychologically that any information may exacerbate the illness. Fine judgement is called for, and in our experience such instances are rare and do not include every case of mental illness". When hospital records were rated by two staff, and separately by two patients, respectively 80 and $84 \%$ of 50 psychiatric case notes contained at least one 'offensive' comment, whereas for 25 general medical records the rates were 24 and 
Table 2. Number (\%) of patients givng a 'favourable' response'

\begin{tabular}{llll}
\hline Questionnaire item & $\begin{array}{l}\text { Psychiatric } \\
\text { patients } \\
(\boldsymbol{n = 7 3 )}\end{array}$ & $\begin{array}{l}\text { Diabetic } \\
\text { patients } \\
(\mathbf{n = 8 4 )}\end{array}$ & $\begin{array}{l}\text { Odds ratio } \\
\text { (95\% confidence interval) }\end{array}$ \\
\hline Understanding & $71(97)$ & $79(94)$ & $0.4(0.08-2.4)$ \\
Omissions & $66(90)$ & $83(99)$ & $7.6(0.9-64.2)$ \\
Outlook & $61(84)$ & $78(93)$ & $2.6(0.9-7.2)$ \\
Upset caused & $59(81)$ & $80(95)$ & $4.8(1.5-15.2)^{2}$ \\
Opinion on access & $57(78)$ & $77(92)$ & $3.1(1.2-8.0)^{2}$ \\
Accuracy & $53(73)$ & $77(92)$ & $4.2(1.6-10.5)^{2}$ \\
Wrong emphasis & $52(71)$ & $75(89)$ & $3.2(1.3-7.4)^{2}$ \\
Helpful information & $35(48)$ & $47(56)$ & $1.4(0.7-2.6)$ \\
\hline
\end{tabular}

1. See text for the definition of 'favourable'.

2. Statistically significant because $95 \%$ confidence interval does not include one.

36\%, respectively (Crichton et al, 1992). 'Chronic schizophrenic' was rated as offensive whereas 'chronic diabetic' was not. The threshold for achieving 'offensiveness' may have been set too low (Howard \& Lovestone, 1993). Three patients with paranoid psychosis were excluded from our study, and it may be that their responses would have been more adverse than those of the other psychiatric patients (Bernadt et al, 1991).

Does a patient have a right to know everything about his/her state of health? Since the answer is self-evidently yes, occasional adverse effects of such knowledge should not in themselves embargo the right. This argument would annul the provision of the Act which enables access to be denied if it is 'likely to cause serious harm' to the patient. Less legalistic reasons for free access to medical records include reducing the inequality of power of the doctor in relation to the patient, enhancing trust and communication between the two, and fostering health education (Baldry et al, 1986; Laughane \& Stafford, 1996).

\section{Appendix: questionnaire stems}

1. Understanding: how well could you understand the doctor's letter?

2. Accuracy: so far as you can tell was the information in the doctor's letter accurate? That is, do you think that what has been written about you is true?

3. Omissions: are there any important points you feel should have been included in the letter and which were left out?

4. Upset caused: did you find anything in the letter upsetting?

5. Wrong emphasis: so far as you can tell, was there any wrong emphasis in the doctor's letter? Was something important played down or something unimportant over-emphasised?

6. Overall impression: was it a good idea for you to read the doctor's letter about you?
7. Helpful information: has the doctor's letter provided helpful information for you?

8. Outlook: do you think it makes you optimistic or pessimistic to read the letter?

\section{Acknowledgement}

We thank Dr Graham Dunn for statistical advice.

\section{References}

Altman, J. H., Reich, P., Kelly, M. J., et al (1980) Patients who read their hospital charts. New England Journal of Medicine, 382. 169-171.

BALDRY, M., CHEAL, C., FISHER, B., et al (1986) Giving patients their own records in general practice: experience of patients and staff. British Medical Journal, 292, 596-598.

Bernadt, M.. Gunning, L. \& Quenstedt, M. (1991) Patients' access to their own psychiatric records. British Medical Journal, 303, 967.

BIRD. A. P. \& WALI, M. T. I. (1986) Our patients have access to their medical records. British Medical Journal. 292. 595-596.

CoHEn. J. (1969) Statistical Power Analysis for the Behavioural Sciences. New York: Academic Press.

Crichton. P.. Douzenis, A., Leggatt, C., et al (1992) Are psychiatric case-notes offensive? Psychiatric Bulletin. 16. $675-677$.

Essex, B., DoIG, R. \& RENShaw, J. (1990) Pilot study of records of shared care for people with mental illnesses. British Medical Journal. 300.1442-1446.

HOWARD, R. \& LOVESTONE. S. (1993) Are psychiatric casenotes offensive? Psychiatric Bulletin. 17, 244.

KoskY, N. \& BURNS. T. (1995) Patient access to psychiatric records: experience in an inpatient unit. Psychiatric Bulletin, 19, 87-90.

LAUGHANE, R. \& STAFFORD, A. (1996) Access to records and client held records for people with mental illness. A literature review. Psychiatric Bulletin. 20, 338-341.

MCFARLANE, M. D.. BOWMAN, R. G. \& MACINNES, M. (1980) Patient access to hospital records. Canadian Joumal of Psychiatry, 25, 497-502.

MCKENZIE, C. R. \& CHARLSON, M. E. (1986) Standards for the use of ordinal scales in clinical trials. British Medical Journal, 292. 40-43. 
Miller, R., MorRow, B., Kaye. M., et al (1987) Patient access to medical records in a forensic centre: a controlled study. Hospital and Community Psychiatry. 38, 1081-1085.

NoRUSIS, M. J. (1990) SPSS/PC+ Aduanced Statistics 4.0. Chicago. IL: SPSS Inc.

Office OF POPUlation Censuses and SuRveys (1970) Classification of Occupations 1970. London: HMSO.

ParRot, J.. Strathdee, G. \& BROWN, P. (1988) Patient access to psychiatric records: the patients' view. Joumal of the Royal Society of Medicine. 81, 520-522.

PRICE, J. S. \& ASCH, R. (1990) Writing to the patient. Psychiatric Bulletin, 14, 467-469.

PRIEST, R. G. (1986) Data Protection Act - suject access to personal health information (DA 8523): DHSS consultation paper. Psychiatric Bulletin. 10. 185.

ROTH, L. H., WOLFORD. J. \& MEISEl, A. (1980) Patient access to records: tonic or toxin? American Joumal of Psychiatry, 137. 592-595.
SERGEANT, H. (1986) Should psychiatric patients be granted access to their hospital records? Lancet, $i$. 1332-1335.

Stein, E.. FUREdY, M.. Simonton, M., et al (1979) Patient access to medical records on a psychiatric inpatient unit. American Joumal of Psychiatry, 136, 327-329.

Arun Jha, Consultant Psychiatrist, West Herts Community Health NHS Trust, Logandene, Hertfordshire; *Morris Bernadt, Senior Lecturer, Department of Psychological Medicine, King's College Hospital, 103 Denmark Hill, London SE5 9RS; Ken Brown, Consultant Physician, Elizabeth Sawicka, Consultant Physician, and George Stein, Consultant Psychiatrist, Farnborough Hospital, Kent

*Correspondence

CR62 'Not Just Bricks and Mortar': Report of the Working Group on the size, staffing, structure, siting and security of new acute adult psychiatric in-patient units, $£ 7.50$, April 1998

To inform the planning of new acute in-patient units for adult mental health.

CR63 Gender Identity Disorders in Children and Adolescents: Guidance for Management, £5.00, April 1998

Offers guidance in the management and therapeutic interventions with children and adolescents and their families.

CR64 Managing Deliberate Self-Harm in Young People, £5.00, April 1998 Provides guidance on managing young people up to the age of 16 (including young people with learning disabilities) who deliberately harm themselves.

Available from Booksales, Royal College of Psychiatrists, 17 Belgrave Square, London SWIX 8PG (Tel. $+44(0) 1712352351$, extension 146). The latest information on College publications is available on the INTERNET at: www.rcpsych.ac.uk 